\title{
Streamflow sensitivity to climate and land cover changes: Meki River, Ethiopia
}

\author{
D. Legesse ${ }^{1}$, T. A. Abiye ${ }^{2}$, C. Vallet-Coulomb ${ }^{3}$, and H. Abate ${ }^{1}$ \\ ${ }^{1}$ Addis Ababa University, Department of Earth Sciences, P. O. Box 1176, Addis Ababa, Ethiopia \\ ${ }^{2}$ School of Geosciences, University of the Witwatersrand, Johannesburg, South Africa \\ ${ }^{3}$ CEREGE-CNRS/UMR 6635, B.P. 80, 13545 Aix-en-Provence cedex 04, France
}

Received: 1 June 2010 - Published in Hydrol. Earth Syst. Sci. Discuss.: 12 July 2010

Revised: 9 November 2010 - Accepted: 11 November 2010 - Published: 17 November 2010

\begin{abstract}
Impacts of climate and land cover changes on streamflow were assessed using a hydrological modeling. The precipitation runoff modeling system of the US Geological Survey was modified in order to consider wetlands as a separate hydrological response unit. Initial model parameters were obtained from a previously modeled adjacent catchment and subsequent calibration and validation were carried out. The model calibration and validation periods were divided into three. The calibration period was a five years period (1981-1986). The validation period was divided into two: validation 1 (1986-1991) and validation 2 (19962002). Model performance was evaluated by using joint plots of daily and monthly observed and simulated runoff hydrographs and different coefficients of efficiency. The model coefficients of efficiency were 0.71 for the calibration period and 0.69 and 0.66 for validation periods 1 and 2 , respectively. A "delta-change" method was used to formulate climatic scenarios. One land cover change scenario was also used to assess the likely impacts of these changes on the runoff. The results of the scenario analysis showed that the basin is more sensitive to increase in rainfall $(+80 \%$ for $+20 \%)$ than to a decrease $(-62 \%$ for $-20 \%)$. The rainfall elasticity is $4: 1$ for a $20 \%$ increase in rainfall while it is $3: 1$ for a $20 \%$ reduction. A $1.5^{\circ} \mathrm{c}$ increase in temperature resulted in a $6 \%$ increase in potential evapotranspiration and $13 \%$ decrease in streamflow. This indicates that the watershed is more elastic to rainfall increase than temperature. The proposed land cover scenario of converting areas between 2000 to $3000 \mathrm{~m}$ a.s.l. to woodland also resulted in a significant decrease in streamflow $(11.8 \%)$. The study showed that properly calibrated and validated models could help understand likely impacts of climate and land cover changes on catchment water balance.
\end{abstract}

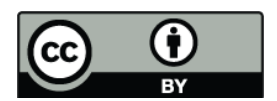

Correspondence to: D. Legesse (dagnachewl@yahoo.com)

\section{Introduction}

Climate change can cause significant impacts on water resources through changes in the hydrological cycle. The change in temperature and precipitation components of the cycle can have a direct consequence on the quantity of evapotranspiration and runoff components. Consequently, the spatial and temporal water resource availability, or in general the water balance, can be significantly affected, which clearly amplifies its impact on sectors like agriculture, industry and urban development (Hailemariam, 1999).

Land cover change, associated with the intensification of agriculture, cattle raising and urbanization, could have a profound influence on the hydrological processes in small watersheds and at a regional level (Mendoza et al., 2002). Streamflow plays an important role in establishing some of the critical interactions that occur between physical or ecological processes and social or economic processes (Choia and Dealb, 2008).

The purpose of water resources management is often to mitigate or prevent the adverse impacts of excessive runoff or shortage of water. Hydrological models have served as a valuable tool in water resources management for many years and are usually used to simulate the impacts of proposed land use/ land cover and climate change scenarios and to evaluate management strategies. Generally, hydrological models provide a framework in which to conceptualize and investigate the relationships between climate and water resources (Leavesley, 1994; Lazzaratto et al., 2006; Kunstmann and Stadler, 2005; Choi and Deal, 2008). Global Climate Models that simulate long-term trends in climate (rainfall, temperature, humidity) are often unsuitable for regional scale studies because of the course grid-size resolution. Consequently, there is a strong need for hydrological modeling tools that can be used to assess the likely effects of land cover as well as climate changes on the hydrological cycle at a catchment scale. 
The Ethiopian Rift system hosts a series of lakes that are mainly fed by water flowing from the surrounding highlands and escarpments. Over the past few decades there has been a lot of activities that have modified the land use/land cover in the region (Jansen et al., 2009). Moreover, the hydrological dynamics has been strongly modified by intensive agricultural activities. This has a direct impact on the lakes downstream. Therefore, it is very important to understand the functioning of these lake catchments and their hydrological response under different land use/cover and climate change scenarios. Moreover, the water resources development of the basin requires a judicious planning for the protection of the fragile ecosystem.

This study will focus on a catchment scale hydrological modeling of the Meki River basin, which is part of the Central Main Ethiopian Rift lakes system.

The main objectives of this study are:

1. Test and validate a modified Precipitation Runoff Modeling System (PRMS) and assess the model performance in the basin.

2. Assessing the impacts of land cover and climate change scenarios on the catchment's streamflow.

For this study a physically based distributed-parameter catchment scale hydrological model called PRMS was selected. The model was then modified to accommodate the prevailing conditions of the catchment as described below.

\section{Description of PRMS}

PRMS is a modular-design, physically based deterministic, distributed-parameter modeling system developed by the US Geological Survey to evaluate the impacts of various combinations of precipitation, climate, and land use on streamflow, sediment yields, and general basin hydrology (Leavesley et al., 1983). Basin response to normal and extreme rainfall events can be simulated to evaluate changes in waterbalance relationships, flow regimes, flood peaks and volumes, soil-water relationships, sediment yields, and groundwater recharge (Leavesley et al., 1983). PRMS is physically based in that each component of the hydrological system is simulated with known physical laws or empirical relations formulated on the basis of measurable watershed characteristics. The modular design of PRMS provides a flexible modeling capability while allowing changes and adaptations to certain specific catchments. Detailed description of the model as well as the model itself can be obtained from Leavesley et al. (1983) and the USGS website.

PRMS is integrated in the Modular Modeling System (MMS), which is a modeling platform that has parameteroptimization, sensitivity analysis as well as real-time display capabilities. PRMS can be run in daily and storm mode time scales. The daily mode simulates daily average runoff and the storm mode simulates runoff at time intervals that may be shorter than a day.

PRMS components are designed around the concept of partitioning a watershed into units on the basis of characteristics such as slope, aspect, vegetation type, and soil type and precipitation distribution. Each unit is considered homogeneous with respect to its hydrological response and is called a hydrological response unit (HRU) (Leavesley et al., 1983; Flugel, 1995).

A water balance and an energy balance are computed daily for each HRU. The sum of the responses of all HRU's, weighted on a unit area basis, produces the daily system response and streamflow from the watershed. Partitioning provides the ability to impose land use or climate change on parts or all of a watershed, and to evaluate the resulting hydrological impacts on each HRU and on the total watershed. In PRMS a watershed is conceptualized as a series of reservoirs whose outputs combine to produce the total watershed response: the impervious-zone reservoir, the soil-zone reservoir, the unsaturated subsurface reservoir and the groundwater reservoir (Leavesley et al., 1983). Daily total streamflow from the watershed's outlet is the sum of surface runoff, subsurface interflow and baseflow.

One of the compelling reasons for the choice of this model is that it has already been tested in the same region with an apparent success (Legesse et al., 2003). Although the two catchments have similar watershed and climatic contexts, they also exhibit differences. One marked difference is the fact that the Meki River traverses a vast wetland area that modifies its hydrological behavior. Since wetlands are not explicitly represented in the original PRMS, it was modified to take into account the wetland as one HRU. This is more appropriate than trying to use the original model as it is, which may well provide a 'good' result through calibration, a situation which Goswami and O'Connor (2010) referred to as models that are "right for the wrong reason".

\subsection{Model building using the modular modeling system}

The original PRMS doesn't take wetlands and lakes into account and hence couldn't be directly used for this study. The original soil moisture balance module was replaced by a new one modified by Mastin and Vaccaro (2002). The general schematics of the various modules constituting PRMS is shown in Fig. 1.

In the modified soil moisture balance module, a new soil type representing water-covered areas was added (Mastin and Vaccaro, 2002). For this soil type, the actual evapotranspiration was set to $1769 \mathrm{~mm}$, which approximates the mean annual evaporation from Lake Ziway (Vallet-Coulomb et al., 2001). Moreover, land cover parameters were made to represent bare ground as suggested by Mastin and Vaccaro (2002). This way the vast wetland area in the Meki catchment was modeled as one HRU. 


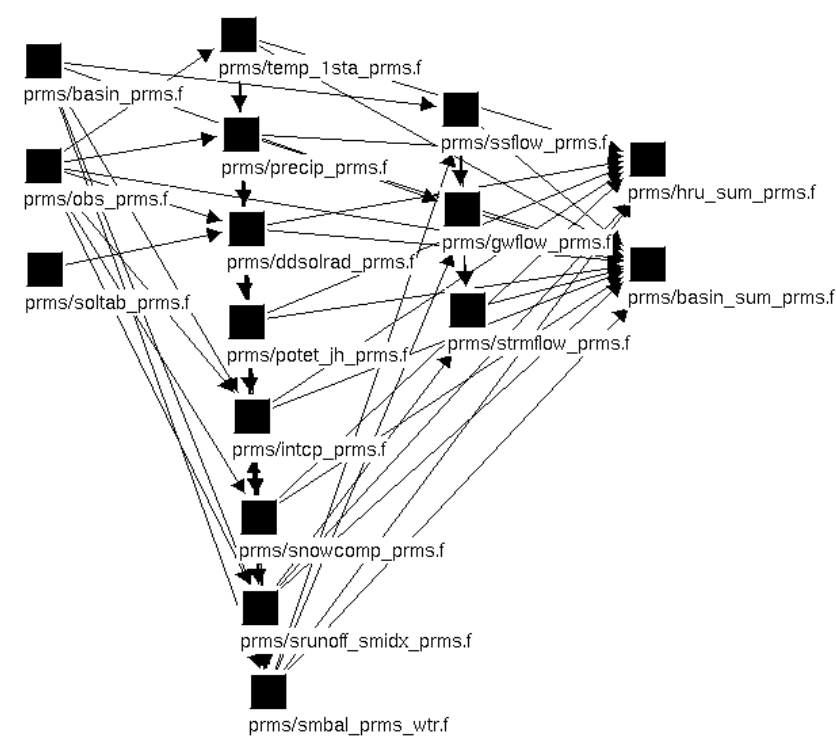

Fig. 1. Specific modules linked to build PRMS for Meki Catchment.

\section{Description of the Meki Basin}

The Meki River basin, which is part of the Ziway-Shalla basin, is located in the northern part of the Main Ethiopian Rift (Fig. 2). The area extends from a chain of mountains upstream, called the Guraghe Mountains, to the low-lying Ziway Lake. The total gauged basin area of Meki is about $2154 \mathrm{Km}^{2}$. Topography of the area is primarily determined by the rift system of faulting. The study area lies within altitudes ranging from $3600 \mathrm{~m}$ a.s.l. in the west to $1600 \mathrm{~m}$ a.s.l. in the rift floor with a mean elevation of $2056 \mathrm{~m}$ a.s.l. The upper riches of the basin are steep and mountainous while the lower basin is flat with a broad valley (Fig. 3).

The western plateau of the Gurage highlands with elevation ranging from 3500 to $3600 \mathrm{~m}$ a.s.l. are the perennial sources of the Meki River while the tributaries in the escarpment and rift floor are intermittent sources. The Meki River drains the western mountains and escarpments including a vast swampy area and travels for about $100 \mathrm{~km}$ before draining to Ziway Lake. The highland is characterized by higher drainage density than the escarpments and the flat rift floor areas. Rift faults have affected the drainage of the area both by determining the river courses and by impounding river water and causing some marshy areas (Chernet, 1982).

The land cover of the study area can be categorized mainly as agricultural, with open woodlands, forest, and water bodies. Some Irrigation activities are practiced along the courses of the Meki River. Teff (Eragostis tef) is a leading cereal crop on the hilly areas covered by deep soils and higher rainfall while maize and wheat are more prevalent on the valley floor with lower rainfall. Haricot beans (Phaseolus vulgaris), horse beans (Vicia fabal L), peas (Pisum sativum L), chickpeas (Cicer arietinum L) and Lentil (Lens culinaris Medik)

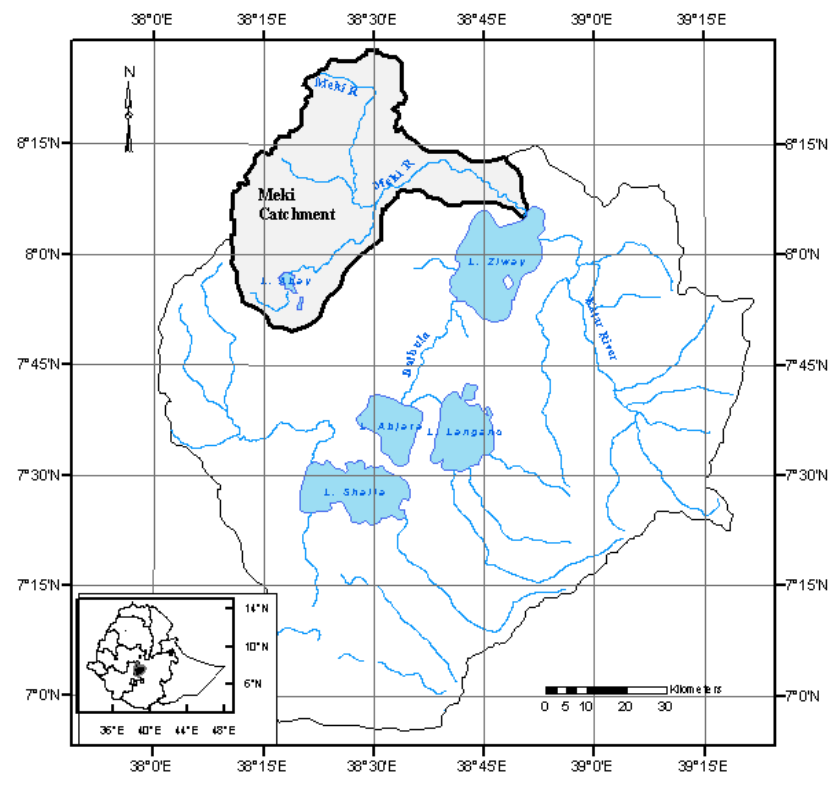

Fig. 2. Location Map of the Meki Catchment with in the ZiwayShalla basin in the main Ethiopian Rift (MER).

are major pulse crops cultivated in the area. Onion, tomato, cabbage, chili pepper, carrot, and fruits are also widely cultivated.

The study area has soils closely related to the parent material and the degree of weathering (Makin et al., 1976). Basalt, ignimbrite, acidic lava, volcanic ash and pumice, and riverine and lacustrine alluvium are the main parent materials (Di Paola, 1972). Generally, soil types in the area could be grouped into three. The first group is a welldrained deep reddish brown to red friable clays to clay loams with strong structure. The second group of soil is a welldrained, moderately deep-to-deep dark gray or brown, friable silty loam to sandy loam soils with moderate structure and good moisture storing properties. The third group of soil is dark grayish, free draining friable silty loam to sandy loam with moderate structure and good moisture storing properties (Fig. 3). The soil data for this study was extracted from the Soil and Terrain Database for northeastern Africa CD-ROM (FAO, 1998).

Climate of the study area consists of three ecological zones: humid to dry humid, dry sub-humid or semi arid and semiarid or arid lands (Makin et al., 1976). Temperature and rainfall in the area show strong variations with altitude. Mean annual temperature ranges from about $15^{\circ} \mathrm{C}$ in the highlands to around $20^{\circ} \mathrm{C}$ in the rift (Fig. 4). The average annual rainfall also varies spatially and ranges from around $650 \mathrm{~mm}$ in the rift floor to more than $1200 \mathrm{~mm}$ in the highlands.

The Indian and Atlantic Oceans are the sources of moisture for almost all rains in Ethiopia (Degefu, 1987). Three main seasons characterize the study area: the first one is the long rainy season in summer, which lasts from June to 


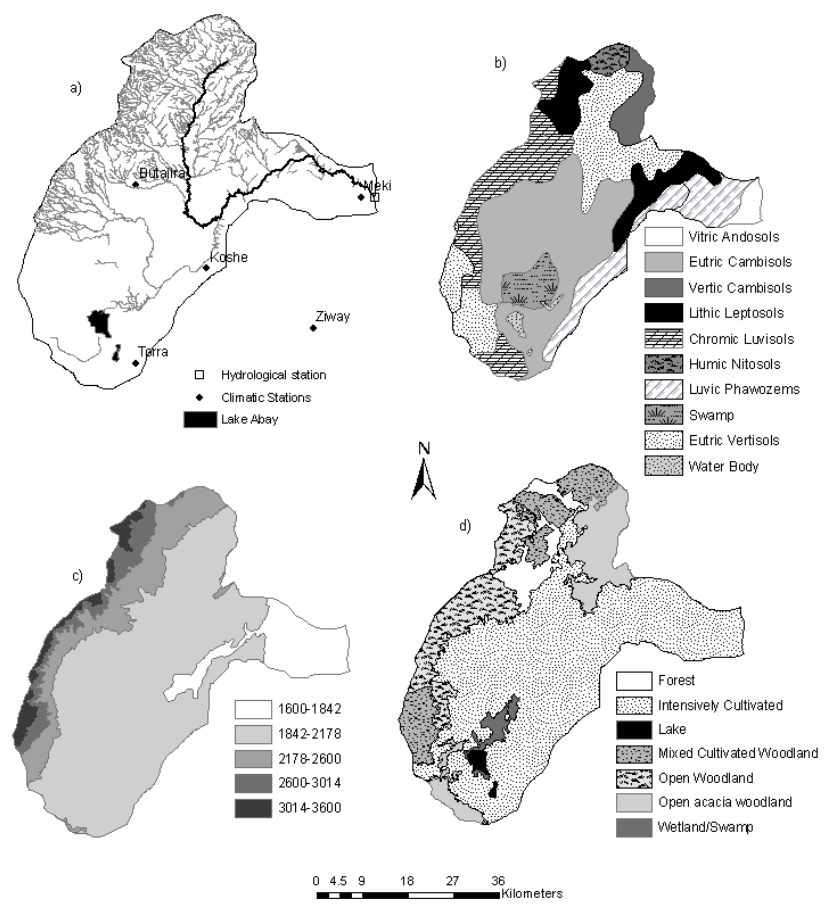

Fig. 3. (a) Drainage network, (b) Soil map, (c) Topographic elevation $\mathrm{m}$ a.s.l. and (d) Generalized land use map of Meki River Catchment.

September and locally known as "kiremt". The "kiremt" season is primarily controlled by the seasonal migration of the Inter Tropical Convergence Zone (ITCZ), which lies to the north of Ethiopia at that time. According to Degefu (1987), the "kiremt" rain represents $50-70 \%$ of the average yearly total. The second is the dry period, which extends between October and February and locally known as "bega". In "bega" the ITCZ lies to the south of Ethiopia when the northeasterly trade winds traversing Arabia dominates the region. Degefu (1987) indicated that occasional rains during this period bring $10-20 \%$ of the yearly average. The "bega" season is known as the main harvest season in the area. The third season, which is locally known as "belg" is of a "small rain" season accounting for $20-30 \%$ of the annual amount, and stays from March to May. Figure 4 shows mean monthly rainfall distribution for stations in the Meki catchment.

\section{Model application to Meki River Basin}

\subsection{Model data preparation}

In this study PRMS was calibrated and verified using the daily-mode flow simulation. Measured daily runoff data from the Meki town gauging station was obtained from the Ministry of Water Resources and used in this study directly with no adjustments. Missing values were replaced by -9.99

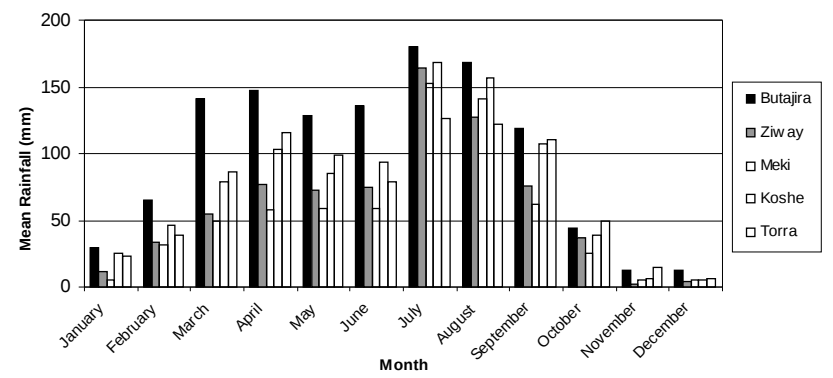

Fig. 4. Mean Monthly rainfall at some stations in the Meki Catchment.

in the model and these periods were avoided from model calibration and validation.

Measured climate data including daily rainfall and maximum and minimum air temperatures were obtained from the National Meteorological Services Agency (NMSA). Since solar radiation data was not available for any of the stations in the study area, daily solar radiation data measured at Addis Ababa (about $160 \mathrm{Km}$ North of the study area and found at mean elevation of about $2500 \mathrm{~m}$ ) was used. After estimating correlation coefficients between adjacent stations and loading factors, statistical regression method was used to fill in missing climatic data values, which represent less than 5\% of the total data. All the available climatic and hydrological data cover a period of 25 years from January 1980 to December 2005.

\subsection{Delineating Hydrological Response Units (HRUs)}

The distributed parameter capabilities of PRMS are enabled by partitioning a watershed into sub-areas that are assumed to be homogeneous in their hydrological responses, termed hydrological response units (HRUs). There is no hard and fast rule on how to delineate hydrological response units (Leavesley et al., 1983). The crucial assumption for each HRU is that the variation of the hydrological process dynamics within the HRU must be small compared with the dynamics in a different HRU. Heterogeneity within an individual HRU is accounted for by computing spatially weighted averages for each characteristic (Flügel, 1995).

In this study partitioning was made based on basin characteristics such as soil, vegetation, elevation, slope, aspect and mean annual rainfall distribution using ESRI's ArcGIS®. Topographic maps at a scale of 1:50000 were digitized to generate Digital Elevation Model, slope, and aspect maps needed to delineate the HRUs. Existing digital soil map (FAO, 1998) and satellite image derived land use/ land cover map were integrated in a GIS.

Daily precipitation data recorded at five meteorological stations (four in the catchment and one nearby station were interpolated using kriging technique to obtain mean monthly and annual spatial distribution maps of the precipitation in 


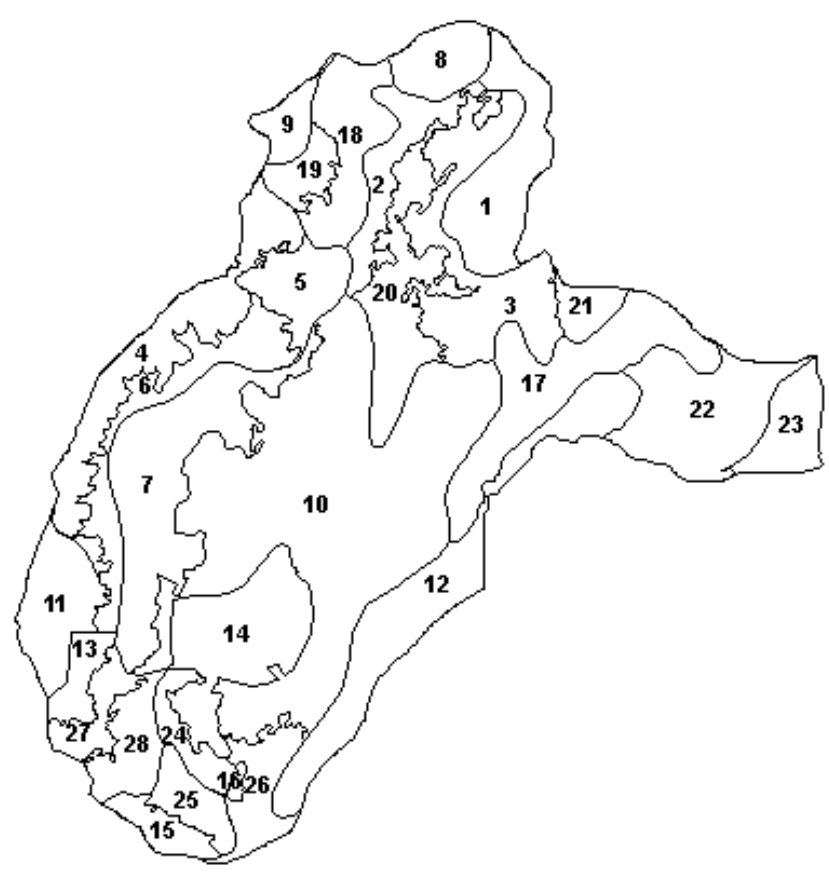

Fig. 5. Delineated HRUs and their respective numbers.

the basin. These layers were brought together and spatial overlay analysis was used to delineate the HRUs. After simplification of the resulting polygons obtained from the overlay process, 28 HRUs were delineated for the basin (Fig. 5).

In this study, initial estimates of parameter and coefficient values for the basin were taken largely from a previous PRMS modeling study (Legesse et al., 2003) on Ketar River basin, an adjacent basin, with similar hydrological context, except for the physical parameters. Physical parameter values were computed for the watershed using GIS analysis.

Soil texture and available water holding capacity are the two soil characteristics that are used to define model parameters in the PRMS. Soil texture classes and depth were derived from the FAO Soil and Terrain database. The other important soil parameter is the available water holding capacity of the soil profile in the study area, which depends on both soil texture and the rooting depth of the predominant vegetation. Unfortunately, very little is known about the rooting depths of plants in the region. For this study, values estimated by Leopold et al. (1989) based on relationships linking vegetation class, soil texture, rooting depth and moisture capacity of soil were adopted.

The depth of the upper soil layer is user-defined and was assumed to consist of the top half of the maximum root zone since this is the area in which more than half the root density is found (Evans and Sneed, 1996). PRMS has predefined land cover types and hence original land cover classes were assigned one of the four vegetation types defined in PRMS (bare soil, grass land, shrubs or trees). Vegetation cover density (percentage of green vegetation on a patch of land, HRU in this case) was estimated using normalized difference vegetation index (NDVI) from Landsat ETM+ satellite images.

Although the geology of the Meki River watershed is non-uniform, one subsurface and one groundwater reservoirs were used to describe the unsaturated subsurface and the groundwater systems. In other words, excess soil-zone water from each of the $28 \mathrm{HRUs}$ in the Meki River watershed is routed into the same subsurface and groundwater reservoirs. Values representing the physical characteristics of the HRUs are summarized in Table 1.

\subsubsection{Model calibration, validation and results}

The availability of concurrent runoff and climate data primarily dictated the selection of the time periods used for model calibration and validation. A period of one year (1980-1981) was used for model initialization. The purpose of model initialization is to estimate initial conditions in the basin at the beginning of a simulation period. The model calibration and validation periods in this study were divided in to three. The calibration period was a five years period (1981-1986). The validation period was divided in to two: validation 1 (19861991) and validation 2 (1996-2002). This was due to missing discharge records between the two validation periods.

The model was first run in a daily runoff-prediction mode with parameter values that were largely adopted from an earlier similar work in the adjacent Ketar River catchment by Legesse et al. (2003). After selection of initial parameter values, a daily sensitivity analysis was run to identify parameters that had the most effect on predicting daily runoff during the calibration period.

Results of the sensitivity analysis indicated that the basin response is more sensitive to the rainfall correction factor (RAIN_ADJ), a monthly temperature adjustment factor for calculation of PET (jh_coef), soil moisture related parameter SOIL_MOIST_MAX and subsurface flow related parameter SSRCOEF_LIN and surface runoff related parameter CAREA_MAX. The model results were also fairly sensitive to two other parameters related to surface runoff (SMIDX_EXP) and (SMIDX_COEF). These parameters were selected for the calibration process. After preliminary model results were examined, the purpose of model calibration was to estimate realistic model parameter and coefficient values for the study area so that the PRMS model closely simulates the hydrological processes of the watershed.

A trial and error adjustment of the selected parameters was performed in an attempt to adjust volume and timing and the flow components of the simulated runoff hydrograph. Selected parameter values were adjusted upward and downward manually between each model run for the calibration period (1981-1986). Finally, an automatic calibration method provided by MMS, the Rosenbrock optimization technique (Leavesley et al., 1983, 1996), was applied to better improve the model performance. 
Table 1. Some physical characteristics of HRUs delineated for Meki Catchment.

\begin{tabular}{|c|c|c|c|c|c|c|c|}
\hline HRU & Area $\left(\mathrm{Km}^{2}\right)$ & Cover type $^{\mathrm{a}}$ & Soil type ${ }^{b}$ & Elevation (m) & Slope (\%) & Aspect & SMAX $(\mathrm{mm}) \mathrm{c}$ \\
\hline 1 & 87.05 & 3 & 3 & 2158.80 & 9.89 & $\mathrm{~S}$ & 350 \\
\hline 2 & 54.03 & 1 & 3 & 2401.81 & 17.98 & $\mathrm{E}$ & 75 \\
\hline 3 & 122.49 & 3 & 3 & 2022.95 & 8.51 & $\mathrm{~S}$ & 350 \\
\hline 4 & 112.79 & 3 & 3 & 2922.84 & 33.65 & $\mathrm{E}$ & 350 \\
\hline 5 & 46.92 & 3 & 3 & 2410.96 & 20.58 & $\mathrm{E}$ & 350 \\
\hline 6 & 75.51 & 3 & 3 & 2456.17 & 21.31 & SE & 350 \\
\hline 7 & 148.51 & 1 & 2 & 2173.22 & 7.64 & $\mathrm{E}$ & 200 \\
\hline 8 & 39.35 & 1 & 3 & 2592.99 & 8.84 & $\mathrm{E}$ & 75 \\
\hline 9 & 22.69 & 3 & 3 & 3140.54 & 21.60 & $\mathrm{SE}$ & 350 \\
\hline 10 & 456.27 & 1 & 2 & 1907.02 & 3.34 & $\mathrm{E}$ & 200 \\
\hline 11 & 61.45 & 1 & 3 & 2939.50 & 15.73 & $\mathrm{E}$ & 75 \\
\hline 12 & 136.41 & 1 & 2 & 1906.49 & 4.49 & $\mathrm{E}$ & 200 \\
\hline 13 & 23.03 & 1 & 3 & 2409.17 & 12.33 & $\mathrm{SE}$ & 75 \\
\hline 14 & 108.21 & 0 & 4 & 1843.82 & 2.16 & SE & $1769^{\delta}$ \\
\hline 15 & 22.90 & 3 & 3 & 2153.64 & 18.64 & SE & 350 \\
\hline 16 & 2.83 & 0 & 4 & 1820.56 & 0.57 & $\mathrm{NE}$ & $1769^{\delta}$ \\
\hline 17 & 116.12 & 1 & 2 & 1814.10 & 4.59 & $\mathrm{SE}$ & 200 \\
\hline 18 & 69.83 & 1 & 3 & 2730.40 & 12.03 & $\mathrm{E}$ & 75 \\
\hline 19 & 23.82 & 1 & 3 & 2895.68 & 10.66 & $\mathrm{E}$ & 75 \\
\hline 20 & 90.55 & 1 & 3 & 1959.50 & 7.06 & $\mathrm{SE}$ & 150 \\
\hline 21 & 20.20 & 1 & 3 & 1886.73 & 3.32 & $\mathrm{E}$ & 150 \\
\hline 22 & 107.02 & 1 & 2 & 1719.62 & 1.39 & $\mathrm{E}$ & 200 \\
\hline 23 & 39.95 & 1 & 2 & 1671.28 & 1.04 & $\mathrm{E}$ & 200 \\
\hline 24 & 25.15 & 1 & 2 & 1856.00 & 6.36 & $\mathrm{E}$ & 200 \\
\hline 25 & 29.89 & 1 & 3 & 1931.19 & 7.31 & $\mathrm{E}$ & 150 \\
\hline 26 & 42.65 & 1 & 2 & 1886.41 & 4.71 & $\mathrm{~S}$ & 200 \\
\hline 27 & 27.62 & 1 & 3 & 2171.14 & 9.46 & $\mathrm{SE}$ & 150 \\
\hline 28 & 41.10 & 3 & 3 & 2062.53 & 19.75 & $\mathrm{SE}$ & 350 \\
\hline
\end{tabular}

a $0=$ Bare or Water Body, $1=$ Grass (includes cultivated lands), $2=$ Shrub, $3=$ Trees (includes mature forests and woodlands); $\mathrm{b} 1=$ Sand, $2=$ Loam, $3=$ Clay, $4=$ Water; $\mathrm{c}$ Maximum available water holding capacity of the soil profile in $\mathrm{mm}$; d (Ayenew, 1998).

Simulation results from the modified PRMS model were examined both graphically and statistically (Figs. 6, 7, Table 2). We used the coefficient of determination $r^{2}$, defined as the squared value of the coefficient of correlation according to Bravais- Pearson, Nash-Sutcliffe efficiency $E$ (Nash and Sutcliffe,1970), and Index of agreement $d$ (Willmott, 1981). Each of these methods of efficiency criteria has its merits and demerits as is well explained in Krause et al. (2005).

The mean volume of the simulated runoff is generally greater than the observed runoff values for most of the simulation periods. The model performed well in simulating dry season flows (base flow) for both validation and calibration periods. It also produced reasonably good results in simulating peak discharge values. However, some of the more complex hydrographs are not well-captured. This could be attributed eithre to discharge measurement errors or inadequate model conceptualization for some of the more complex flow regimes. The coefficients of efficiency were 0.71 for the calibration period and 0.69 and 0.66 for validation periods 1 and 2 , respectively.
Overall, it can be concluded that the PRMS model simulated the timing and volume of streamflow for the watershed reasonably well. The three components of the hydrograph are well represented (Fig. 7). A Nash-Sutcliffe efficiency $(E)$ of 0.71 and an index of agreement $(d)$ of 0.9 are obtained between the observed and simulated runoff values for the calibration period indicating a very good fit between the two. Moreover, the very close mean and standard deviation values between the two indicates that the model has well simulated the overall flow both during peaks and low flows. Though relatively small, the Nash-Sutcliffe simulation efficiency values fulfilled the requirements suggested by Santhi et al. (2001) for $E_{\mathrm{NS}}>0.5$.

One of the main objectives of the calibration was to have a realistic flow component of the simulated flow hydrograph. The simulated hydrographs for the calibration period were composed mostly of subsurface flow (43.4\%) followed by groundwater flow $(32.1 \%)$ and finally surface runoff $(24.5 \%$; Fig. 7). A simple base flow separation done on the Meki River discharge has also shown a similar trend for the base flow (Dribssa, 2006). The relative proportion of the surface 

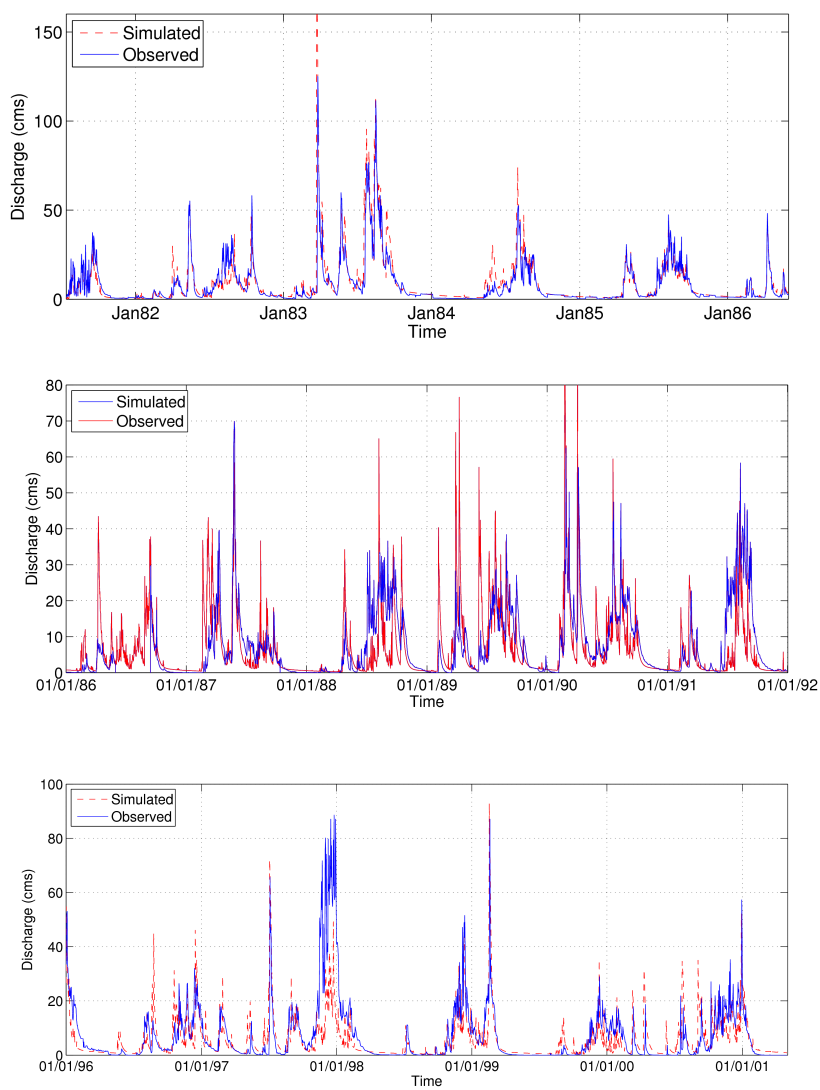

Fig. 6. Daily observed and simulated discharge of Meki river for the (a) Calibration period, (b) validation period 1 and (c) Validation period 2

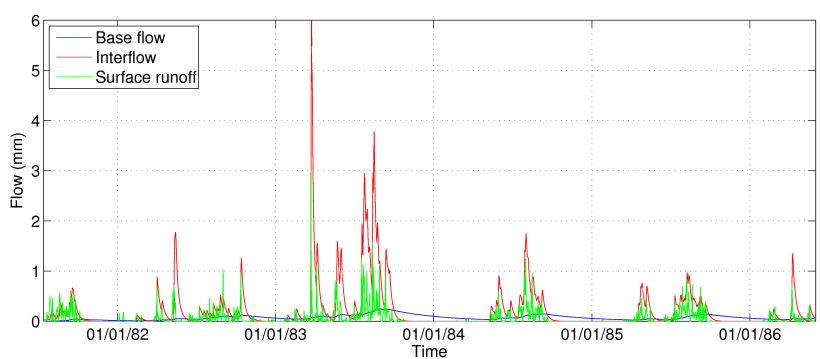

Fig. 7. The three flow components of the daily simulated discharge at the outlet of the Meki River.

runoff is smaller due to the fact that there is a vast wetland in the middle part of the catchment that may act as a retention basin favoring more subsurface flow.

The fit between observed and simulated runoff is even better at a monthly time step indicating that it has well captured the seasonality (Fig. 8). Results of mean monthly runoff simulations seemed to correspond better with observed values with $R^{2}$ value of 0.81 for the calibration period. The monthly coefficient of efficiency was calculated to be 0.74 and 0.72 for the first and second validation periods, respectively.
Table 2. Statistical summary of simulation results for the calibration and validation periods. Meki River catchment.

\begin{tabular}{lrrr}
\hline & Calibration & Validation1 & Validation2 \\
\hline Mean Observed & 8.2 & 7.27 & 6.12 \\
Mean Simulated & 9 & 6.59 & 6.9 \\
Std. Dev. Observed & 12.9 & 9.68 & 9.17 \\
Std. Dev. Simulated & 14.8 & 10.07 & 9.58 \\
R2 & 0.7 & 0.53 & 0.61 \\
Nash-Sutcliffe, $E$ & 0.71 & 0.69 & 0.66 \\
Index of agreement, $d$ & 0.9 & 0.79 & 0.88 \\
\hline
\end{tabular}

\subsection{Scenario simulations}

Water resources are likely to be severely affected by changing climate. This is mainly because of the fact that even a minor long-term change in temperature and precipitation may have significant impacts on the hydrological cycle especially at the basin scale (Loe et al., 2001). Consequently, it is quite essential to identify the level of impact on such resources.

In this study simulations under different scenario conditions have been performed in order to analyze the impacts of possible climate and in land cover changes on streamflow. This involves calibrating and validating the hydrological model using present conditions and running the model with parameters and input data corresponding to the proposed scenario conditions and comparing the two simulations.

\subsubsection{Climatic scenarios}

In this study we used the "delta-change" method to perturb observed historical climatology (Prudhomme et al., 2002) in the form of change factors that are applied to each day. Such scenarios do not necessarily present a realistic set of changes (Fowler et al., 2007). They are usually adopted for exploring system sensitivity prior to the application of more credible, model-based scenarios (Mearns et al., 2001). In this study a $20 \%$ change in precipitation (during summer and spring rainy seasons as well as dry season) and a $1.5^{\circ} \mathrm{C}$ increase in temperature were considered. Although arbitrary, this kind of increase in rainfall is not unrealistic as it has already been proposed to explain the formation of the once joined large lake of the Ethiopian Rift Valley (Street, 1979) and which now has shrunk to from the current lakes.

Results of the simulated scenarios revealed that the runoff volume is sensitive to both temperature and rainfall changes. The runoff was found to be more sensitive to increase in rainfall than to its decrease. It also showed that increase in temperature also reduces the runoff significantly. Simulated runoff values for all scenarios were compared with simulated runoff values for the first validation period (19861991). An increase in temperature by $1.5^{\circ} \mathrm{C}$ resulted in $13 \%$ decrease in simulated runoff and an increase of potential evapotranspiration by $6.02 \%$. An increase in daily rainfall 

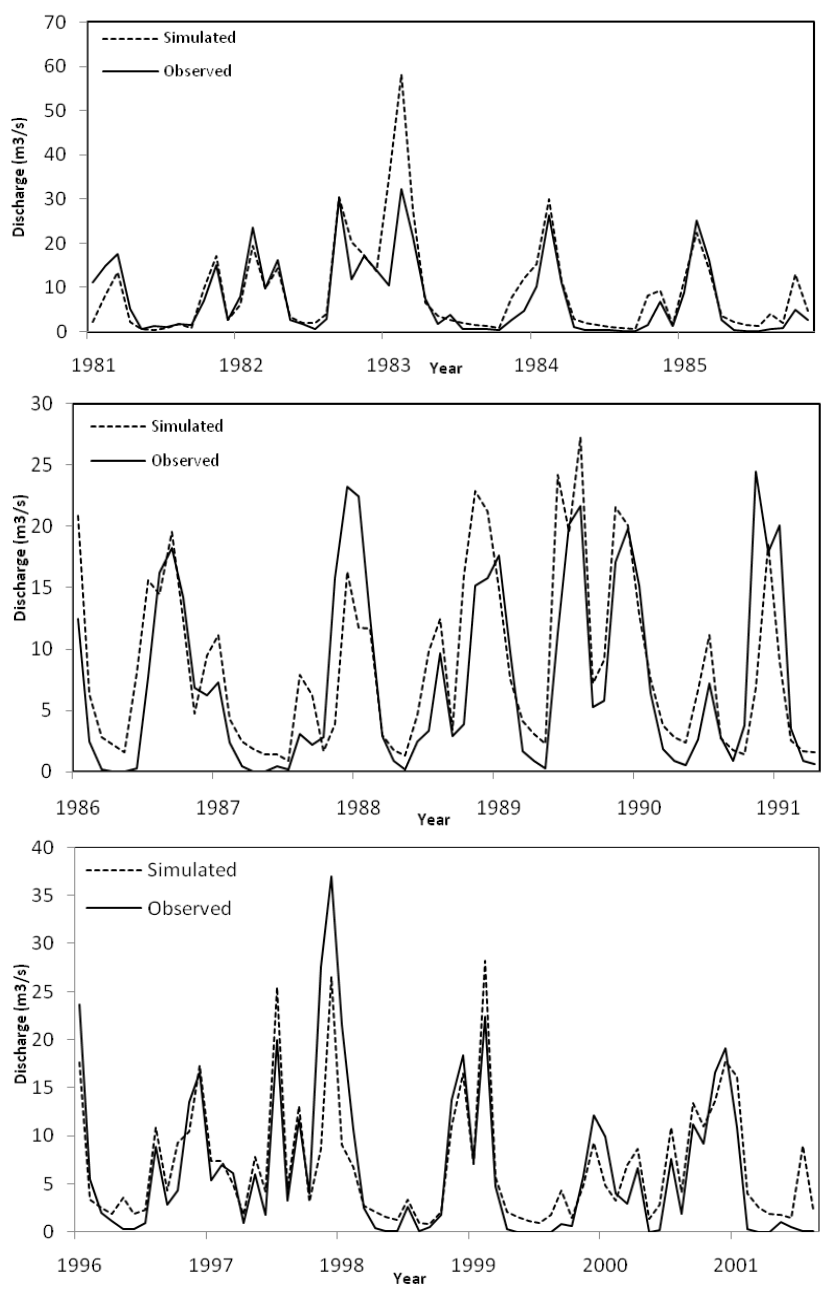

Fig. 8. Mean monthly simulated and observed discharge at the outlet of Meki River for (a) the calibration period, (b) Validation period 1 and (c) Validation period 2

over the entire year by $20 \%$ resulted in $80 \%$ increase in simulated runoff while a decrease in rainfall by the same magnitude led to $61.9 \%$ decrease in simulated runoff. For the summer season (June to September), an increase in rainfall by $20 \%$ brought about $50 \%$ increase in simulated runoff and a decrease in rainfall by similar magnitude caused a decrease in simulated runoff by $38 \%$. For the spring season (March to May), an increase in runoff by $27 \%$ resulted from an increase in rainfall by $20 \%$ and the simulated runoff decreased by $20.6 \%$ for a decrease by the same amount. The results of the rainfall and temperature scenario analysis are shown in Figs. 9 and 10, respectively.

The very high rainfall elasticity of streamflow observed for the $20 \%$ increase in daily rainfall throughout the year may in part be attributed to errors in calibration or model structure as discussed by Sankarasubramanian et al. (2001). However, the strong similarity of these results with those from the adja-

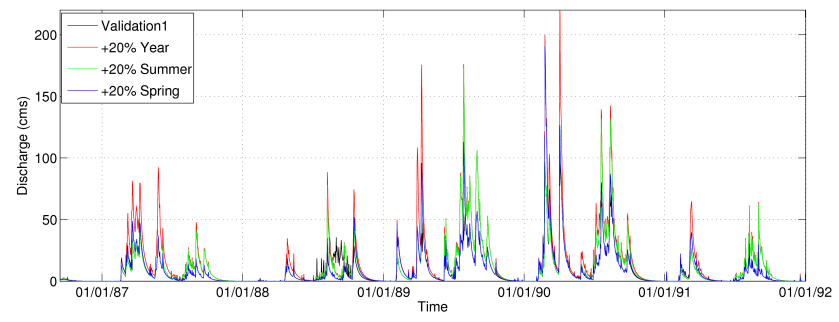

Fig. 9. Simulated discharge for validation period 1 and selected rainfall scenarios.

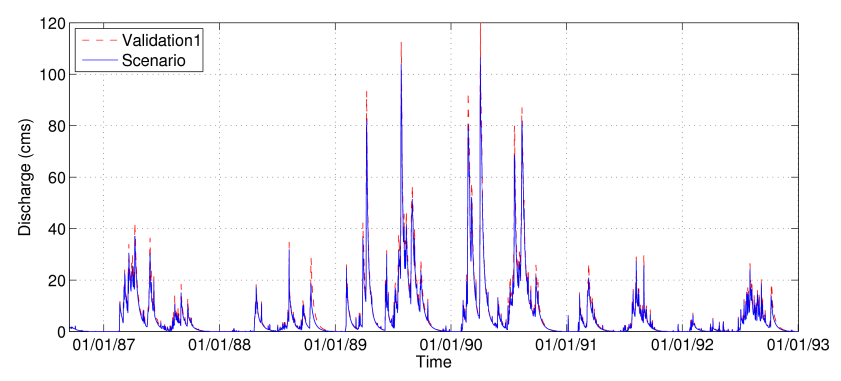

Fig. 10. Simulated discharge for validation period 1 and temperature scenario.

cent Ketar catchment (Legesse et al., 2003) may suggest that the approach is reproducible at least in a similar hydrological context but with appropriate model formulation.

\subsubsection{Land cover scenario}

Land use/land cover changes occur in the country as a whole and in the Ziway-Shala basin in particular (Woldu and Tadesse, 1990) due to increasing population, which has almost doubled in the country over the past 40 years (CSA, 1999). It is thus essential to analyze the possible impacts of these changes on streamflow at different scales. In this study, one scenario of land cover change was assumed to assess the impact of this change on the runoff.

Parameters that were adjusted with respect to changes in the vegetation cover included maximum soil water holding capacity (SMAX), and maximum interception storage. The change in runoff resulting from the change in land cover is determined by comparing the simulated flows using the calibrated parameters with that obtained with parameters estimated for the assumed land cover change.

Assuming that the currently intensively cultivated land between 2000 and $3000 \mathrm{~m}$ a.s.l. was once covered by dense woodland and by introducing the corresponding parameters to this change, the model produced an increase in daily evapotranspiration of $2.2 \%$ and a decrease in the mean daily river flow of about $11.8 \%$ with respect to the actually simulated value. This decrease could be attributed to the increased water retention capacity by the more vegetated areas there by reducing quickflow. However, the impacts of land 
cover change on streamflow is a rather contentious one as is well illustrated by some previous works (Seibert and Jeffery, 2008; Andreassian, 2004; Hewlett, 1982). This kind of change detection modeling could give a better result if used with a model that treats vegetation in a dynamic way. Here, the changes made are static and assume a one-time change. However, it still is considered as a better way of evaluating these impacts (Seibert and Jeffery, 2010).

\section{Concluding remarks}

In this study a modified precipitation modeling system (PRMS) was developed to assess the impacts of climate and land cover changes on the runoff of Meki River basin using the Modular Modeling System (MMS). Initial parameter estimates were taken mainly from literature during preliminary model run, which were later modified through calibration. Both manual and automatic calibration techniques were used in this study on selected model parameters.

According to the analysis of the flow components of the simulated hydrograph, majority of the streamflow comes from subsurface flow, which was estimated to be $42 \%$ on average for the entire simulation period. The contribution of the groundwater flow to streamflow was also significant, $39 \%$ on average. The contribution of surface runoff to streamflow was found to be the least which was estimated to be about $19 \%$ on average for the entire simulation period.

An arbitrary $20 \%$ change in rainfall and $1.5^{\circ} \mathrm{C}$ increase in temperature were considered using the 'delta-change' method. Rainfall change scenarios were introduced both on the entire year and on seasonal basis. This was to assess the sensitivity of the catchment runoff to both seasonal and yearround rainfall changes. This kind of analysis is particularly important for the region as it has a bi-modal rainfall distribution. Much of the agricultural activity in the region is rainfed and often suffers from seasonal as well as annual rainfall variability. Results of the scenario analyses showed that the Meki River runoff is differently sensitive to temperature and rainfall changes. The catchment was found to be more elastic to rainfall increase than to temperature. The rainfall elasticity is $4: 1$ for $20 \%$ increase in Rainfall and 3:1 for $20 \%$ reduction in Rainfall.

Scenario analyses were performed considering one variable at a time and keeping other values unchanged and hence the combined effects resulting from a proposed scenarios are not addressed in this study. One of the main reasons for not considering combined scenario analyses is the fact that this kind of models do not consider vegetation dynamics in a realistic way. One way of addressing such impacts could be by using a coupled dynamic vegetation - water-balance models.

Most physically based models cannot fully account for the complexity and heterogeneity of processes occurring in the watershed (Yeung, 2005). The accuracy of the model calibration is dependent on the accuracy of the input data. Errors associated with the assumed distribution of rainfall over the watershed affect model results. For example, overestimation of streamflow in the model in general may have resulted from overestimation of rainfall in the watershed or the poor performance of the model in basin with large wetland areas. Rainfall distribution in the study area was calculated by using stations on highlands outside the catchment due to the insufficient distribution of rainfall stations in the basin. The available rainfall stations are not well distributed but rather limited to lower altitude areas.

Meanwhile, this study should be extended by considering more scenarios of changes in land use and land cover, soil conditions and other climate variables in addition to the changes in precipitation and temperature. Continuing studies; however, should consider the wide range of uncertainties associated with models and try to reduce these uncertainties by the use of different GCM outputs, and appropriate downscaling techniques. Application of a number of GCMs can help to generate a more "reliable" ensemble mean through spatial and temporal downscaling. However, such a comprehensive work can only be more realistic at a regional scale and can not completely replace the approach adopted in this work.

The studied area is unique and the vital resources within the broader Rift Valley Lakes System provide invaluable benefits with regard to agriculture, recreation, drinking water needs, industrial development, fish and wildlife habitat, and biodiversity (Ayenew and Legesse, 2007). It is also one of the most densely populated areas of the country. Lake Ziway, which is directly fed by the flows from the Meki River catchment, is highly susceptible to any natural and/or man-made activities within the catchment. It is therefore essential that appropriate watershed management policies be put in place in order to promote a more sustainable environment. This kind of study may contribute to this endeavors through the application of different development scenarios.

Acknowledgements. We would like to express our sincere gratitude to the MAWARI project (French Ministry of Foreign Affairs: 2003-45) for its generous financial support, ESCARSEL(French National Research Agency ANR-VMC-06-VULN-010), for financing DL to spend several short stays at CEREGE and Department of Earth Sciences (AAU) for logistics and other supports. Our thanks also go to the Ethiopian Meteorological Services Agency and the Ministry of Water Resources for providing us with daily meteorological and river discharge data free of charge. We would also like to extend our sincere gratitude George Leavesley and S. L. Markstrom of the USGS for their devotion in providing assistance on their freely available model.

Edited by: M. Gebremichael 


\section{References}

Abiye, T. A., Legesse, D., and Abate, H.: The impact of climate change on groundwater recharge: a case study from the Ethiopian Rift. Groundwater and Climate in Africa, Proceedings of the Kampala Conference, June 2008, Kampala, Uganda, 174 IAHS Publ. 334, 2009.

Albek, M., Ülker Bakır Öğütveren, U. B., and Albek, E.: Hydrological modeling of Seydi Suyu watershed (Turkey) with HSPF, J. Hydrol., 285, 260-27, doi:10.1016/j.jhydrol.2003.09.002, 2004.

Andréassian, V. : Waters and forests: from historical controversy to scientific debate, J. Hydrol., 291(1-2), 1-27, 2004.

Ayenew, T.: The hydrogeological system of the lake district basin, Central Main Ethiopian Rift, Published PhD thesis, Free University of Amsterdam, The Netherlands, p. 259, 1998.

Ayenew, T. and Legesse, D.: The changing face of the Ethiopian rift lakes and their environs: call of the time, Lakes \& Reservoirs: Research and Management, 12, 149-165, 2007.

Beven, K: Topmodel: a critique, Hydrol. Process., 11, 1069-1085, 1996.

CSA: Statistical Abstract, Ethiopian Central Statistical Authority, Addis Ababa, Ethiopia, 1999.

Chernet, T.: Hydrogeology of the lakes region, Ethiopia (lakes Ziway, Langano, Abiyata, Shalla, Awassa), Memoir no. 7, The Provisional Military Government of Socialist Ethiopia, Ministry of Mines and Energy, Ethiopian Institute of Geological Surveys, Addis Ababa, 1982.

Choia, W. and Dealb, M. B.: Assessing hydrological impact of potential land use change through hydrological and land use change modeling for the Kishwaukee River basin (USA), J. Environ. Manage., 88, 1119-1130, 2008.

Di Paola, G. M.: The Ethiopian Rift Valley (between $7^{\circ} 00^{\prime}$ and $8^{0} 40^{\prime}$ lat. North), B. Volcanol., 36, 1-44, 1972.

Dribssa, A.: Groundwater-surface water interaction and analysis of recent changes in hydrologic environment of lake ziway catchment, Unpub. Msc thesis, Addis Ababa University, Addis Ababa, Ethiopia, 95 pp., 2006.

Evans R. and Sneed R.E: Soil, water and crop characteristics important to irrigation scheduling, North Carolina Cooperative Extension Services, Publication number AG 452-1, USA, 1996.

FAO: Allen, R. G., Pereira, L. S., Raes, D., and Smith, M.: Crop evapotranspiration - Guidelines for computing crop water requirements - FAO Irrigation and drainage paper 56, FAO Food and Agriculture Organization of the United Nations, Rome, 1998.

Flügel, W.-A.: Delineating hydrological response units by geographical information system analyses for regional hydrological modelling using PRMS/MMS in the drainage basin of the River Bröl, Germany, in: Scale Issues in Hydrological Modelling, edited by: Kalma, J. D. and Sivapalan, M., Wiley, New York, 181-194, 1995.

Goswami, M. and O'Connor, K. M.: A “monster" that made the SMAR conceptual model "right for the wrong reasons", Hydrol. Sci. J., 55(6), 913-927, 2010.

Hewlett, J. D.: Forests and floods in the light of recent investigation. In: Hydrological Processes of Forested Areas, 543-559, National Research Council of Canada Publ., 20548, Ottawa, 1982.

IPCC: Climate Change 2001, in: The Scientific Basis. Contribution of Working Group I to the Third Assessment Report of the Intergovernmental Panel on Climate Change, edited by: Houghton,
J. T., Ding, Y., Griggs, D. J., Noguer, M., van der Linden, P. J., Dai, X., Maskell, K., and Johnson, C. A., Cambridge University Press, Cambridge, UK and New York, NY, USA, 881 pp., 2001.

Fowler, H. J., Blenkinsopa, S., and Tebaldi, C.: Review Linking climate change modelling to impacts studies: recent advances in downscaling techniques for hydrological modelling, Int. J. Climatol., 27, 1547-1578, 2007.

Hailemariam, K.: Impact of Climate Change on the Water Resources of Awash River Basin, Ethiopia, Climate Res., 12, 9196, 1999.

Krause, P., Boyle, D. P., and Base: Comparison of different efficiency criteria for hydrological model assessment, Advances in Geosciences, 5, 89-97, 2005.

Kunstmann, H. and Stadler, C.: High resolution distributed atmospheric-hydrological modelling for Alpine catchments, J. Hydrol., 314, 105-124, doi:10.1016/j.jhydrol.2005.03.033, 2006.

Lazzarottoa, P., Stammc, C., Prasuhnb, V., and Fluhlera H.: A parsimonious soil-type based rainfall-runoff model simultaneously tested in four small agricultural catchments, J. Hydrol., 321, 2138, doi:10.1016/j.jhydrol.2005.07.038, 2006.

Leavesley, G. H.: Modeling the effects of climate change on water resources-a review, Climatic Change, 28, 159-177, 1994.

Leavesley, G. H., Litchy, R. W., Troutman, B. M., and Saindon, L. G.: Precipitation-runoff modeling system: user's manual. US Geological Survey Water Resources Investigative Report 834238, Denver, Colorado, 207 pp., 1983.

Leavesley, G. H., Restrepo, P. J., Markstrom, S. L., Dixon, M., and Stannard, L. G.: The modular modeling system (MMS) user's manual: US Geological Survey Open-File Report 96-151, 151 pp., 1996.

Legesse, D., Vallet-Coulomb, D., and Gasse, F.: Hydrological Response of a Catchment to Climate and Land use Changes in Tropical Africa: Case Study South Central Ethiopia, J. Hydrol., 275, 67-85, 2003.

Lenhart, T., Eckhardt, K., Fohrer, N., and Frede, H.-G.: Comparison of two different approaches of sensitivity analysis, Phys. Chem. Earth, 27, 645-654, 2002.

Leopold, B. L. and Dunne, T.: Water in Environmental Planning. Freeman, San Fransisco, 815 pp., 1978.

Maidment, D. R.: Hand book of hydrology, McGraw Hall, New York, 660 pp., 1993.

Mastin, M. C. and Vaccaro J. J.: Watershed models for decision support in the Yakima River basin, Washington, US Geological Survey Open-File Report 02-404, Tacoma, Washington, 2002.

Makin, M. J., Kingham, T. J., Waddams, A. E., Birchall, C. J., and Eavis, B. W.: Prospects for irrigation development around Lake Ziway, Ethiopia, Land Res. Study. Division, Ministry of Overseas Development, 26, Tolworth, UK, 270 pp., 1976.

Mearns, L. O., Hulme, M., Carter, T. R., Leemans, R., Lal, M., and Whetton, P.: Climate Scenario Development, In: Climate Change 2001: The Scientific Basis. Contribution of Working Group I to the Third Assessment Report of the Intergovernmental Panel on Climate Change, edited by: Houghton, J. T., Ding, Y., Griggs, D. J., Noguer, M., van der Linden, P. J., Dai, X., Maskell, K., and Johnson, C. A., Cambridge University Press, Cambridge, UK and New York, NY, USA, 881 pp., 2001.

Mendoza, M., Bocco, G., and Bravo, B.: Spatial prediction in hydrology: status and implication in the estimation of hydrological 
processes for applied research, Prog. Phys. Geog., 26(3), 319338, 2002.

Nash, J. E. and Sutcliffe, J. V.: River flow forecasting through conceptual models, Part I - A discussion of principles, J. Hydrol., 10, 282-290, 1970.

Sankarasubramanian, A., Vogel, R. M., and Limbrunner, J. F. : Climate elasticity of streamflow in the United States, Water Resour. Res., 37(6), 1771-1781, 2001.

Santhi, C., Arnold, J. G., Williams, J. R., Dugas, W. A., Srinivasan, R., and Hauck, L. M.: Validation of the SWAT model on a large river basin with point and nonpoint sources, J. Am. Water Resour. As., 37(5), 1169-1188, 2001.

Seibert, J. and McDonnell, J. J.: Land-cover impacts on streamflow: a change-detection modelling approach that incorporates parameter uncertainty, Hydrol. Sc. J., 55(3), 316-332, 2010.

Street, A. F.: Late Quaternary lakes in the Ziway-Shala Basin, southern Ethiopia, $\mathrm{PhD}$ thesis, Cambridge University, Cambridge, UK, 457 pp., 1979.
Vallet-Coulomb, C., Legesse, D., Gasse, F., Travi, Y., and Chernet, T.: Lake evaporation estimates in tropical Africa (Lake Ziway, Ethiopia), J. Hydrol., 245(1-4), 1-18, 2001.

Willmott, C. J.: On the validation of models, Physical Geography, 2, 184-194, 1981.

Woldu, Z. and Tadesse, M.: The vegetation in the lakes region of the rift valley of Ethiopia and the possibility of its recoveries, SINET: Ethiopian J. Sci., 13, 97-120, 1990.

Xu, Z. X., Ito, K., Shultz, G. A., and Li, J. Y.: Integrated hydrological Modeling and GIS in water resource management, J. Comput. Civil Eng., 15(3), 217-224, 2001.

Yeung, C. W.: Rainfall-runoff and water-balance models for management of the Fena Valley Reservoir, Guam, US Geological Survey Scientific Investigations Report 2004-5287, 52 pp., 2005. 